\title{
Child abuse and neglect: a major public health issue and the role of child and adolescent mental health services
}

\author{
Mike Shaw, ${ }^{1}$ Margaret De Jong ${ }^{2}$
}

The Psychiatrist (2012), 36, 321-325, doi: 10.1192/pb.bp.111.037135

${ }^{1}$ Tavistock and Portman NHS Foundation Trust, London, UK; ${ }^{2}$ Great Ormond Street Hospital for Children NHS Foundation Trust, London, UK

Correspondence to Mike Shaw (mshaw@tavi-port.nhs.uk)

First received 28 Sep 2011, final revision 6 Feb 2012, accepted 16 Mar 2012

\begin{abstract}
Summary Child and adolescent mental health services (CAMHS) make an important contribution to the assessment and treatment of abuse and neglect in children. However, the provision of services is patchy and we see the present political and economic environment as providing opportunities but also threats. In this editorial we examine some of the barriers to CAMHS involvement, emphasise the potential public health benefits of improving the service, and provide some examples of how CAMHS could develop its involvement in partnership with Social Services and the family courts.
\end{abstract}

\section{Declaration of interest None.}

We are child and adolescent psychiatrists who work in the National Health Service (NHS) with abused and neglected children and their families. Our jobs involve multidisciplinary and multiagency working, complex assessments and cutting-edge interventions. We find this work fascinating and deeply satisfying, although we are aware that this has not in the past been a popular area for psychiatrists and other mental health specialists in which to engage, resulting in a lack of clinical research and stilted service development. As a result of some of the government policies, some child and adolescent mental health services (CAMHS) now support children 'looked after' and 'in care'; however, mental health input for this population remains patchy across the country.

We are writing now because it is a classic moment of opportunity and threat. We are encouraged by The Munro Review of Child Protection, ${ }^{1}$ which tries to free social workers from bureaucracy and encourage more autonomous use of clinical judgement. We also see potential in the government's drive to raise the profile of public health. ${ }^{2}$ On the other hand, the chief medical officer's initiative, 'Bearing Good Witness, ${ }^{3}$ to promote multidisciplinary expert assessments in the family court, has been slow to get off the ground. ${ }^{4}$ Furthermore, in the present adverse economic environment the government is considering reducing the involvement of experts in the family court ${ }^{5}$ and cutting their fees. ${ }^{6}$ Financial restraint also threatens the continued development of looked-after children (LAC) teams, which has been a very welcome initiative.

\section{A public health perspective}

Child abuse and neglect affect a substantial number of children. In their study of children in high-income countries, Gilbert et $a l^{7}$ discovered that about $4-16 \%$ of children are physically abused and one in ten is neglected or psychologically abused every year. Further, the study revealed that between 5 and $10 \%$ of girls and up to $5 \%$ of boys 'are exposed to penetrative sexual abuse and up to three times this number are exposed to any type of sexual abuse'.

Abuse and neglect have an immediate impact on mental health and well-being. The most recent survey by the National Society for the Prevention of Cruelty to Children (NSPCC) suggests that 'severely maltreated' young people aged 11-17 years are six times more likely to have current suicidal ideation than their counterparts who have not been maltreated. ${ }^{8}$

Childhood abuse and neglect is important from a public health perspective because it has long-lasting effects on adult mental health, drug and alcohol misuse, obesity and criminal behaviour. ${ }^{7}$ In women, there is a particularly strong link between penetrative sexual abuse in childhood and adult mental health disorders. For example, using data from a cross-sectional national psychiatric survey, Jonas et $a l^{9}$ found that women who had experienced non-consensual sexual intercourse before the age of 16 had increased rates of common psychiatric disorders (e.g. depression), drug dependence, alcohol dependence, post-traumatic stress disorder and eating disorders, with odds ratios (ORs) ranging from 4.1 to 8.83 (in other words, they were four to nine times more likely to be ill than if they had not been abused). The link was even stronger between nonconsensual sexual intercourse before the age of 16 and psychosis $(\mathrm{OR}=10.14) .{ }^{10}$ Using a very different method, Cutajar et $a l^{11}$ followed a large cohort of sexually abused children over a number of decades. They found that rape in 
early adolescence by more than one perpetrator increased the risk of adult psychotic syndromes by 15 -fold.

Whereas odds ratios provide a measure of the strength of the association between a risk factor and a disorder, the population attributable fraction represents the proportion of disorders that can be ascribed to exposure to a particular risk. In theory, the population attributable fraction indicates how much the prevalence of a disorder would be reduced if the risk factor was eliminated in the population. ${ }^{12}$ Analysing data from the Christchurch Health and Development Study in New Zealand, Fergusson et $a l^{13}$ concluded that eliminating childhood sexual abuse (involving attempted or completed sexual penetration) would reduce the overall rates of mental disorder by $13.1 \%$. In a later study in England, Bebbington et $a l^{10}$ found that reducing contact and non-contact child sexual abuse would reduce the rate of psychosis by $22 \%$.

In real life, particular forms of abuse or neglect rarely occur in isolation. Instead, they are strongly associated with each other and other adversities that harm children's health and development such as domestic violence, parental substance misuse, parental mental health problems, parental intellectual difficulties, parental offending, housing problems, social isolation, displacement and/or persecution. Kessler et $a l^{14}$ examined joint associations of 12 childhood adversities with first onset of 20 DSM-IV disorders in the World Health Organization's World Mental Health Surveys in 21 countries. They found that parental mental illness, child abuse and neglect were the strongest predictors of disorders; that the effects were across all the disorders and countries; and that collectively childhood adversities account for $29.8 \%$ of all mental health disorders. This is almost certainly an underestimate because psychosis was not among the 20 disorders the researchers looked at.

It follows that prevention and early intervention with child abuse and neglect presents a clear opportunity to improve lifetime mental health. ${ }^{15}$ In this editorial, we examine the role of CAMHS in its current reality and in its potential to do more.

\section{CAMHS' involvement with children who are neglected or abused}

A large proportion of abused and neglected children have a psychiatric disorder. An epidemiological study of children and adolescents in Great Britain ${ }^{16}$ found significantly higher rates of difficulty among 'looked-after' children (children in foster care) compared with other socioeconomically disadvantaged children or children in the remaining private household sample; the proportion with at least one ICD-10 psychiatric diagnosis was $46 \%, 15 \%$ and $9 \%$ respectively in each of these categories. We know less about the abused and neglected children who are not yet looked after but it seems reasonable to assume that rates of psychiatric disorder would also be high.

Many children will present with diagnoses (attentiondeficit hyperactivity disorder (ADHD), post-traumatic stress disorder (PTSD), depression, anxiety, conduct disorder) for which the evidence base developed in the CAMHS clinic population is applicable. There is also a growing evidence base for effective treatments specifically targeting children with a maltreatment background or aimed at parent-child interventions. ${ }^{17}$ Cognitive-behavioural approaches are often recommended, and there are now some randomised controlled trials, for example in the treatment of PTSD in sexually abused children. ${ }^{18,19}$ Interventions based on a theoretical understanding of attachment difficulties are very popular, but relatively few have been systematically evaluated. ${ }^{20}$ Evaluated parent-child interaction studies have successfully targeted physical abuse. ${ }^{21}$ Multidimensional Treatment Foster Care is an ambitious and effective treatment programme targeting children in foster care through working with their carers and supporting network. $^{22}$

\section{Barriers to CAMHS' involvement}

Child and adolescent mental health services have historically tended to regard child abuse and neglect as a social problem, requiring a social care solution. Research in the past decade highlighting the high prevalence of mental health problems has contributed to a gradual shift in this attitude. However, despite repeated initiatives such as 'Working Together', ${ }^{23}$ there has been a failure to clarify processes for interagency working and collaboration between CAMHS and Social Services tends to be clumsy. We believe there are complex emotional, historical, political and economic reasons which act as a deterrent to CAMHS' involvement.

The emotional demands of the work can act as a psychological barrier. Abused and neglected children feel very anxious, angry, helpless and hopeless. These feelings are difficult to bear and contribute to splits and rivalries in the professional network. ${ }^{24}$ We find that clinicians working in a well-functioning, multidisciplinary team are better able to cope, especially where there are clear structures for interagency working. The work is challenging also because abused or neglected children find it harder to trust and develop a therapeutic relationship. Similarly, it takes great clinical skill to maintain a therapeutic alliance despite sharing child protection concerns with Social Services. Clinicians can also be reluctant to begin work that could be disrupted by placement moves, although short-term interventions are becoming more widely accepted. ${ }^{25}$

The relatively low referral rate of abused and neglected children to CAMHS may relate to a number of factors, ${ }^{26}$ including the absence of advocacy for the child, underrecognition of mental health problems, and a perception among adoptive parents that common CAMHS treatment approaches such as family therapy may focus on parental difficulties, without fully understanding or acknowledging the extent of the child contribution. ${ }^{27}$ Issues of stigma and shame can make young people reluctant to seek help.

Although there are examples of excellent practice across the country, many overstretched CAMHS' clinics cannot give the work the attention it needs. Tensions exist at the interface between CAMHS and Social Services and also the family justice system. Because nearly all court assessments are done privately or by assessment-only NHS teams, there is frequently a disjunction between the recommendations and the reality of the local CAMHS provision. Moreover, waiting times for CAMHS are usually 
not dynamic enough to respond to the demands of the court and local authority. We believe major structural changes are needed in the way assessments are carried out and treatments are offered.

\section{What should the role of CAMHS be?}

An effective public health strategy for child abuse and neglect requires primary, secondary and tertiary prevention (Box 1). Primary prevention aims to prevent maltreatment in the first instance. It includes education and health promotion among groups at risk. We accept that primary prevention is unlikely to require CAMHS.

Secondary prevention seeks to detect maltreatment at an early stage, when the effect on the child is more limited and reversible. It requires interventions not only to help the child but also to address difficulties in the parent and the parent-child relationship. We believe this is an area where CAMHS has significantly more to offer. We advocate the development of multiagency working with the family court, Social Services, adult treatment services, probation, housing and others to improve outcomes for children. Very often social workers have collected the necessary evidence to initiate care proceedings but lack the training to analyse the evidence. There are cases when children could remain at home if a timely, well-coordinated, multiagency intervention could be deployed. Child mental health professionals have a great deal to offer here.

The Family Drug and Alcohol Court (FDAC) is an example of a more complex secondary prevention programme. It helps families where children are in care proceedings as a result of their parent's substance misuse. It involves collaboration between the family court, child and adult mental health experts, treatment services, social workers, housing services and many more. Parents are given 'a trial for change' to provide the best possible chance to overcome their problems and meet their children's needs in an appropriate timeframe. Interventions include supporting abstinence and lifestyle change, intensive treatment to help parents address the problems driving their substance misuse, treatments to improve the parentchild relationship and treatment of individual children. The programme has been shown to not only improve children's chances of remaining with their family, but also ensure a permanent alternative placement is found more swiftly when staying with their family is not possible. ${ }^{28}$

Tertiary prevention targets children already damaged by abuse and neglect; these are children in long-term foster care, kinship placements and adoptive families. This is an area where CAMHS' role needs to be consolidated. We agree with the authors ${ }^{29-31}$ who advocate universal mental health screening for children entering care.

Rao et $a l^{32}$ argue that CAMHS should only see lookedafter and adopted children with an identifiable psychiatric disorder. We believe impairment is not always well captured by psychiatric diagnosis, as children with early abuse or neglect often present with a complex array of developmental deficits. ${ }^{33,34}$ This is not surprising, considering the range of aetiological factors at play, for example: prenatal exposure to drugs and alcohol, the effects of early trauma on brain development, disrupted or distorted attachment
Box 1 The role of CAMHS in prevention and early intervention with child abuse and neglect

Primary prevention:

- aims to prevent maltreatment in the first instance

- involves education and health promotion among at-risk groups

- unlikely to require direct CAMHS involvement.

Secondary prevention:

- early intervention when the effect on the child is more limited and reversible

- helping children directly and also addressing difficulties in the parent and the parent-child relationship

- requires development of CAMHS-led multiagency interventions working with the family court, Social Services, adult treatment services, probation, housing and others to improve outcomes for children

- possible to improve outcomes for children but also save money in the short term.

Tertiary prevention:

- targeting children already damaged by abuse and neglect

- aims to reduce suffering, promote quality of life and prevent the onset of adult mental health disorders

- requires introduction of universal screening for psychiatric diagnosis and developmental deficits in all children coming into care

- strengthening and extending the role of looked-after children (LAC) teams to assess, treat and monitor children picked up by screening

- requires improved capacities to work with children in short-term placements as well as long-term monitoring of complex cases

- will require additional funding but strong public health argument for long-term savings to the public purse.

processes, and loss of the biological family. A service with acceptance criteria requiring a threshold of psychiatric diagnosis will therefore not meet all the mental health needs of this population.

Good-quality mental health assessments of children and treatment of mental health disorders is a generally undisputed role for CAMHS. More controversial is the timing of interventions, with many CAMHS still arguing that they are unable to offer anything until a child's care situation is stabilised with a long-term care plan in place. Prompt intervention (e.g. for ADHD) can prevent foster placement breakdown. ${ }^{25}$

The introduction of LAC teams in the UK has been welcome, in that it encouraged the development of specialist expertise and also close working across health and social services. However, interventions in LAC services are short term, ending once a child is either rehabilitated or placed in alternative long-term care such as a kinship placement or adoption. We agree with Tarren-Sweeney ${ }^{30}$ that services for looked-after and adopted children should have the capacity to offer long-term monitoring and treatment, unlike the acute intervention model of generic CAMHS. Not only is this a better model for children with 
long-term and complex needs, but it improves the likelihood that we will be able to prevent the onset of adult mental health disorders.

A coherent framework to provide adequate mental health support for this vulnerable population of children requires an agreed referral pathway, clear procedures for interagency working and interdisciplinary structures that facilitate close cooperation between disciplines working within social care, health and the family justice system. A good model would build on current LAC teams, creating specialist teams within CAMHS with expertise in this area. These teams could provide regular consultation to social workers, foster carers, residential workers, and adoption support social workers. An outreach component may help to overcome barriers relating to access. The team could liaise with adult mental health services over child protection issues relating to mental health in a parent. Where appropriate, they could refer children with psychiatric disorders to generic CAMHS for management and treatment. Strong links between the specialist team and generic CAMHS would be needed to prevent fragmentation of care. ${ }^{31}$ The model would be one of triage and consultation as well as implementing treatment in areas that relate specifically to experiences of maltreatment and neglect. There is a need to develop and evaluate new interventions in this area in addition to continued outcome-monitoring of established evidence-based interventions.

\section{Commissioning changes: a challenge and an opportunity}

A period of financial restraint may seem an odd time to be promoting a utopian vision of service restructuring within CAMHS. However, the landscape of commissioning is changing rapidly. This is a time when other agencies, such as social care and the family justice system, are carefully re-evaluating their own approach to their work in this area. Changes within the NHS will lead to new developments in mental health commissioning. If 'health and well-being boards' are introduced, services with a clear public health benefit are more likely to be funded. ${ }^{2}$ Money currently being paid to private experts by local authorities could be diverted into developing local CAMHS. There are some precedents for this in different parts of the country where local multidisciplinary expert witness teams have been initiated. Use of health economists can be invaluable in making the argument for restructuring. An evaluation of the FDAC by an international accountancy firm found that it saves the public purse more than it costs within a year. ${ }^{35}$

It therefore seems an opportunity for CAMHS clinicians and managers to think through how we can best meet the needs of this population by clarifying roles, responsibilities, operational criteria and care pathways. Without this vision there is a risk that commissioning will take place without the benefit of the thoughtful expertise of clinicians and that as a result lack of clarity and patchy provision will prevail. More importantly, an opportunity to link CAMHS to a clear public health strategy will be missed.

\section{About the authors}

Dr Mike Shaw, Consultant Child \& Adolescent Psychiatrist, Tavistock Clinic, London. Dr Margaret De Jong, Consultant Child \& Adolescent Psychiatrist and Honorary Senior Lecturer, Great Ormond Street Hospital for Children NHS Foundation Trust, London, UK.

\section{References}

1 Munro E. The Munro Review of Child Protection: Final Report - A ChildCentred System. Department for Education, 2011.

2 HM Government. Healthy Lives, Healthy People: Update and Way Forward. TSO (The Stationery Office), 2011.

3 Department of Health. Bearing Good Witness: Proposals for Reforming the Delivery of Medical Expert Evidence in Family Law Cases. A Report by the Chief Medical Officer. Department of Health, 2006.

4 Tucker J, Moorehead R, Doughty J. Evaluation of the 'Alternative Commissioning of Experts Pilot' Final Report. Cardiff Law School, 2011.

5 Family Justice Review Panel. Family Justice Review - Final Report. Ministry of Justice, Department for Education, Welsh Government, 2011.

6 Ministry of Justice. Proposals for the Reform of Legal Aid in England and Wales. Ministry of Justice, 2010.

7 Gilbert R, Widom C, Browne K, Fergusson D, Webb E, Janson S. Burden and consequences of child maltreatment in high-income countries. Lancet 2009; 373: 68-81.

8 National Society for the Prevention of Cruelty to Children. Child Abuse and Neglect in the UK Today. NSPCC Research, 2011.

9 Jonas S, Bebbington P, McManus S, Meltzer H, Jenkins R, Kuipers E, et al. Sexual abuse and psychiatric disorder in England: results from the 2007 Adult Psychiatric Morbidity Survey. Psychol Med 2011; 41: 709-20.

10 Bebbington $\mathrm{P}$, Jonas $\mathrm{S}$, Kuipers $\mathrm{E}$, King $\mathrm{M}$, Cooper $\mathrm{C}$, Brugha $\mathrm{T}$, et al. Childhood sexual abuse and psychosis: data from a cross-sectional national psychiatric survey in England. Br J Psychiatry 2011; 199: 29-37.

11 Cutajar MC, Mullen PE, Ogloff, JRP, Thomas SD, Wells DL, Spataro J. Schizophrenia and other psychotic disorders in a cohort of sexually abused children. Arch Gen Psychiatry 2010; 67: 1114-9.

12 Northridge ME. Public health methods - attributable risk as a link between causality and public health action. Am J Public Health 1995; 85 : 1202-3.

13 Fergusson DM, Boden JM, Horwood LJ. Exposure to childhood sexual and physical abuse and adjustment in early adulthood. Child Abuse Neglect 2008; 32: 607-19.

14 Kessler RC, McLaughlin KA, Greif Green J, Gruber MJ, Sampson NA Zaslavsky AM, et al. Childhood adversities and adult psychopathology in the WHO World Mental Health Surveys. Br J Psychiatry 2010; 197: 378-85.

15 Read J, Bentall RP. Negative childhood experiences and mental health theoretical, clinical and primary prevention implications. Br J Psychiatry 2012; 200: 89-91.

16 Ford T, Vostanis P, Meltzer H, Goodman R. Psychiatric disorder among British children looked after by local authorities: comparison with children living in private households. Br J Psychiatry 2007; 190: 319-25.

17 MacMillan HL, Wathen NC, Barlow J, Fergusson DM, Leventhal JM Tuassig HN. Interventions to prevent child maltreatment and associated impairment. Lancet 2008; 3: 35-51.

18 Cohen J, Deblinger E, Mannarino AP, Steer RA. A multisite, randomized controlled trial for children with sexual-abuse-related PTSD symptoms. J Am Acad Child Adolesc Psychiatry 2004; 43: 393-402.

19 Macdonald G, Higgins JPT, Ramchandani P. Cognitive-behavioural interventions for children who have been sexually abused. Cochrane Database Syst Rev 2006; 4: CD001930.

20 Van Horn P, Lieberman AF. Using dyadic therapies to treat traumatized children. In Treating Traumatised Children: Risk, Resilience and Recovery (eds D Brom, R Pat-Horenczyck, J Ford): 210-24. Routledge, 2008. 
21 Tanaka M, Jamieson E, Wathen M, MacMillan HL. Methodological standards for randomized controlled trials of interventions for preventing recurrence of child physical abuse and neglect. Child Abuse Rev 2010; 19: 21-38.

22 Chamberlain $\mathrm{P}$, Reid JB. Comparison of two community alternatives to incarceration for chronic juvenile offenders. J Consult Clin Psychol 1998; 66: 624-33.

23 HM Government. Working Together to Safeguard Children: A Guide to Inter-Agency Working to Safeguard and Promote the Welfare of Children. Department for Children, Schools and Families, 2010.

24 Conway P. Falling between minds: the effects of unbearable experiences on multi-agency communication in the care system. Adoption Fostering 2009; 33: 18-29.

25 Wakelyn J. Transitional psychotherapy for looked-after children in 'short term' foster care. J Soc Work Practice 2008; 22: 27-36.

26 Golding KS. Multi-agency and specialist working to meet the mental health needs of children in care and adopted. Clin Child Psycho Psychiatry 2010; 15: 573-87.

27 Rushton A. A scoping and scanning review of research on the adoption of children placed from public care. Clin Child Psychol Psychiatry 2010; 9 89-106.
28 Harwin J, Ryan M, Tunnard J, Pokhrel S, Alrouh B, Matias C, et al. The Family Drug and Alcohol Court (FDAC) Evaluation Project Final Report. Brunel University, 2011.

29 Romanelli L, Landsverk J, Levitt J, Leslie L, Hurley M, Gries L, et al. Best practices for mental health in child welfare: screening, assessment and treatment guidelines. Child Welfare 2009; 88: 163-88.

30 Tarren-Sweeney M. It's time to re-think mental health services for children in care, and those adopted from care. Clin Child Psychol Psychiatry 2010; 15: 613-26.

31 Street E, Davies M. Constructing mental health services for looked after children. Adoption Fostering 2002; 26: 65-75.

32 Rao P, Ali A, Vostanis P. Looked after and adopted children: how should specialist CAMHS be involved? Adoption Fostering 2010; 34: 58-72.

33 DeJong $M$. Some reflections on the use of psychiatric diagnosis in the looked after or 'in care' population. Clin Child Psychol Psychiatry 2010; 15: 589-99.

34 Tarren-Sweeney M. The mental health needs of children in out-of-home care. Curr Opin Psychiatry 2008; 21: 345-9.

35 Department for Education. Family Drug and Alcohol Court (FDAC) Development Project: Options for Sustainability and Rollout. Department for Education, 2012 (in press) 